\title{
Effect of extrusion and compression moulding on the thermal properties of Nylon-6/Silica Aerogel Composites
}

\author{
Suryanarayanan Krishnaswamy ${ }^{1}$, Lawrence Tinsley ${ }^{2}$, Veronica Marchante ${ }^{1}$, Sri \\ Addepalli $^{2}$, Zhaorong Huang ${ }^{3}$, Hrushikesh Abhyankar ${ }^{1}$ \\ ${ }^{1}$ Centre for Automotive Technology, Cranfield University, UK, ${ }^{2}$ Through-life Engineering \\ Services Centre, Cranfield University, UK, ${ }^{3}$ Surface Engineering \& Nanotechnology Institute, \\ Cranfield University, UK
}

\begin{abstract}
The paper presents the effect of a lower extrusion speed and compression moulding processes on the thermal properties of polyamide 6 (PA-6)/Aerogel composite. Scanning electron and optical microscope images showed that although most of the aerogel was destroyed during extrusion at $65 \mathrm{rpm}$, extrusion at $5 \mathrm{rpm}$ showed better retention of the aerogel structure.

However, when subjected to moulding in a compression press, both composites extruded at different speeds suffered significant damage. Nevertheless, the extruded samples did show a lower thermal conductivity compared to the virgin polymer. Further, it was observed that the sample extruded at $5 \mathrm{rpm}$ had a lower damage coefficient value with an overall loss of around $33 \%$ to the aerogel structure when compared to the material extruded at $65 \mathrm{rpm}$, which endured a structural loss of $41 \%$ to the aerogel in it.
\end{abstract}

\section{Keywords}

Nylon, Aerogel, Extrusion, Thermal conductivity, Composites

\section{Introduction}

Aerogels are materials with a gelatinous structure wherein the liquid is replaced by a gas with almost no shrinkage [1]. This results in an open celled mesoporous structure producing an ultra-lightweight material [2]. Although the potential applications of aerogel are numerous, the most significant application is thermal insulation in transport vehicles, portable coolers, 
cryogenics, pipes, space vehicles, casting moulds and architectural insulation, to name a few [3] [4]; due to its low thermal conductivity of $0.012 \mathrm{~W} /(\mathrm{m} \mathrm{K})$ [5]. Additionally, these materials also have low density $\left(3 \times 10^{3}-1 \times 10^{5} \mathrm{~g} / \mathrm{m}^{3}\right)$, low dielectric constant (1.1-2.0), high specific surface area (500-1200 $\left.\mathrm{m}^{2} / \mathrm{g}\right)$ and low refraction index (1.05) [6][7] values. These properties make aerogel a highly promising candidate for a multitude of thermal protection applications. However, the extreme fragility of this material limits its widespread usage [8].

One method of increasing the strength of the aerogel is to use a binding matrix to combines the mechanical strength of the matrix with the thermal properties of the silica aerogel [3][9]. When considering thermoplastic binding matrices, Mielke and Dungen [10] mixed and moulded various combinations of aerogel with a binder containing an aqueous suspension of magnesium montmorillonite and a thermoplastic styrene/butyl acrylate aqueous polymer emulsion. The authors reported that, in all the cases the thermal conductivity of the composite did not exceed $0.020 \mathrm{~W} /(\mathrm{m} \mathrm{K})$. Vo et al [11] reported a decrease in the thermal conductivity of an extruded thermoplastic foam when cavities filled with aerogel were introduced in the parent material. According to their work, the thermal conductivity of the extruded thermoplastic foam dropped from $45 \mathrm{~mW} /(\mathrm{m} \mathrm{K})$ to $30 \mathrm{~mW} /(\mathrm{m} \mathrm{K})$ for cavities with $9 \mathrm{~mm}$ aerogel and to $27 \mathrm{~mW} /(\mathrm{m} \mathrm{K})$ for cavities with $18 \mathrm{~mm}$ aerogel. In another study, Schmidt and Schwertfeger [3] showed that the addition of aerogel to a polyvinylbutyrale (PVB) matrix results in a decrease in the thermal conductivity of the material wherein the addition of around $90 \%$ (volume fraction) of aerogel resulted in a thermal conductivity close to 25 $\mathrm{mW} /(\mathrm{m} \mathrm{K})$ (compared to $120 \mathrm{~mW} /(\mathrm{m} \mathrm{K})$ for PVB). Kim and Hyun [12] also measured the thermal conductivity of Aerogel/PVB composites and discovered that the thermal conductivity decreased significantly when the volume fraction of the aerogel went above $70 \%$. However, the authors noted that dry mixing of these two materials was challenging due 
to the differences in their materials densities. Although the work also considered wet mixing and dual mixing methods to ensure uniformity, the resultant composites had higher thermal conductivity (for the former) and lower modulus of rupture (for both). Williams et al [13] considered MXD6 polyamide in their work and showed that the thermal conductivity of the aerogel/polyamide composite was around 40\% lower than a neat MXD6 sample ; however, they also report a breakage of the aerogel particles inside the twin screw extruder which could affect the thermal performance of the material.

Thus, it is evident from the literature that the inclusion of aerogel in a thermoplastic binding matrix does result in a material with superior thermal insulation properties. However, as was noted by Kim and Hyun [12], the difference in densities between the material may result in an inhomogeneous dry mix. One alternative to overcome this limitation would be the use of a twin screw extruder. These types of extruders have, amongst other advantages, good mixing abilities, heat transfer, melting and control over a range of temperatures [14]. Additionally, it would be ideal for medium-to-large scale manufacturing as extrusion is a continuous process.

Nevertheless, Williams et al [13] showed that the extrusion process described in their study damaged the aerogel structure. Therefore, the present study explores the possibility of using a lower extrusion speed to improve the retention of the aerogel structure in the composite. The material under investigation is composed of silica aerogel (henceforth referred to as just aerogel) and Polyamide 6 (PA-6/Nylon). To achieve its objective, the paper compares the thermal conductivity of pure PA-6 samples and composites processed using higher $(65 \mathrm{rpm})$ and lower $(5 \mathrm{rpm})$ extrusion speeds by measuring their density, specific heat and the thermal diffusivity values. 


\section{Material and Methods}

To prepare the test specimens, the aerogel and the PA-6 pellets were manually mixed, extruded and chopped in a pelletizer. The material was subsequently moulded into its final shape using a compression press, as this would enable further insight into the effect of the shape forming process on the final properties of the material. The following subsections present the detailed preparatory and manufacturing stages together with assessment techniques used to determine various properties of the material.

\section{Sample Preparation}

Cabot Enova Aerogel IC3110 (particle size 100-700 $\mu \mathrm{m}$ ) and Lanxess Durethan B30 polyamide 6 (PA-6) were used as base materials for the samples. Three different batches were extruded and compression pressed into plaques. The details of these batches are:

- Pure PA-6; run through the extruder twice at $65 \mathrm{rpm}$ (Sample A)

- PA-6 with 0.04 (mass fraction) aerogel; run through the extruder twice at $65 \mathrm{rpm}$ (Sample B)

- PA-6 with 0.04 (mass fraction) aerogel; run through the extruder once at $5 \mathrm{rpm}$ (Sample C)

The Nylon pellets were initially heated in an oven to $80{ }^{\circ} \mathrm{C}$ for 180 minutes to remove moisture. Next, in order to prepare samples B and C, 0.04 mass fraction of aerogel was added to each sample before extrusion and poured into the feeder as one material.

A Rondol Twin Screw extruder with the processing temperatures as set in Table 1, was used to extrude the aerogel and the material was then compressed using the press. 


\begin{tabular}{|c|c|c|c|c|}
\hline Zone 1 & Zone 2 & Zone 3 & Zone 4 & Die \\
\hline $225^{\circ} \mathrm{C}$ & $230^{\circ} \mathrm{C}$ & $235^{\circ} \mathrm{C}$ & $230^{\circ} \mathrm{C}$ & $225^{\circ} \mathrm{C}$ \\
\hline
\end{tabular}

The extruded material (samples A, B and C) was heated to $110^{\circ} \mathrm{C}$ for 270 mins to remove any moisture. Then, it was poured into the mould, which was then placed inside the preheated compression press $\left(230^{\circ} \mathrm{C}\right)$. Initially, both the moulding plates were brought into contact with the mould containing the sample material to facilitate heat conduction into the sample for 11 mins. After this, the pressure was increased to $2.76 \mathrm{MPa}$ for a further 5 mins. The sample was allowed to cool inside the press for 65 mins (maintaining a pressure of $2.76 \mathrm{MPa}$ ). Finally, the mould was removed from the press and left to cool to room temperature outside. For samples B and C, the hold time was increased from 11 mins to 13 mins to account for the presence of the silica aerogel.

\section{Characterization of microstructural and thermal properties}

This section presents the various methods used to measure the properties of the pure epoxy and aerogel/epoxy composites. These properties include density, specific heat capacity and thermal diffusivity. The microstructure of the samples is further characterised using optical and environmental scanning electron microscopes.

Density. The density of each individual plaque (sample) was determined by the equation used to calculate the density of a solid, uniform body [15]. The mass of the sample was measured using a weight balance and the volume was calculated by measuring the dimension of the plaques using a line gauge.

Differential Scanning Calorimetry (DSC). One sample from each batch was subjected to a DSC run in a Thermal Analysis 2920 MDSC instrument. The sample was heated to $400{ }^{\circ} \mathrm{C}$ at 
$5{ }^{0} \mathrm{C} / \mathrm{min}$ under a nitrogen gas flow. The recorded data was then used to calculate the specific heat capacity for each individual sample using the method outlined by O'Neill [16].

Thermal Diffusivity. The thermal diffusivity of each batch was measured using a Thermal Wave Imaging Thermoscope II pulsed thermographic inspection system [17] equipped with a FLIR SC7600 MB Infrared camera. The frame size used was $640 * 512$ pixels (full frame) and the flash pulse length was $10 \mathrm{~ms}$. The acquisition time and frequency were $50 \mathrm{~s}$ and $25 \mathrm{~Hz}$ respectively.

Morphology. The structure of the pressed plaques was studied under a Nikon Optiphot Image Acquisition system with a Leica Application Suite software; magnifications of 5X and 40X were used. Further, the morphology and the chemical composition of samples were analysed using a Philips XL30ESEM environmental scanning electron microscope (ESEM) fitted with an energy dispersive $\mathrm{x}$-ray spectroscope (EDX).

Thermal Conductivity. To calculate the thermal conductivity of the samples, the following formula was used (equation (1)).

$k=(\alpha * \rho * c)$

Where $\mathrm{k}=$ Thermal conductivity in $\mathrm{W} /(\mathrm{m} \mathrm{K}), \alpha=$ Thermal diffusivity in $\mathrm{m}^{2} / \mathrm{s}, \rho=$ Density in $\mathrm{g} / \mathrm{m}^{3}$ and $\mathrm{c}=$ Specific heat in $\mathrm{J} /(\mathrm{g} \mathrm{K})$

\section{Results}

The data from the various experiments are as presented below. Initially, the microstructures of the extruded material (all three samples) were analysed under a scanning electron microscope (ESEM) and an optical microscope. Then, the density, thermal diffusivity and the 
specific heat capacity of the materials were measured using the methodology identified in the previous section.

\section{Morphology}

SEM-EDX. SEM-EDX results of the extruded samples before being compression moulded are as seen in Figure 1, Figure 2 and Figure 3 for samples A, B and C respectively. From the EDX results, it can be inferred that silica was detected in samples B and C. However, further analysis on sample B (Figure 4) showed an almost-continuous presence of silicon and oxygen across an extruded piece, thereby suggesting a uniform dispersion of silica. Additionally, the visual image of the SEM showed homogeneity across the cross section. Therefore, it can be concluded from the results that, although Sample B had silica along with PA-6, the structure of the aerogel had collapsed (almost completely) and only particles of silica have been dispersed uniformly in the PA-6 matrix.

The SEM image (Figure 3) of Sample C showed a more coarse structure when compared to the previous samples; although some extruded pieces of sample B did show some roughness, sample $\mathrm{C}$ had significantly more roughness which can be evidenced from the SEM scans. In addition, the sample was also scattered with small particle-like structures. When one of the structures was analysed (Figure 5), the EDX revealed a higher amount of silicon and oxygen compared to the matrix and previous samples. This was also confirmed by the weight percentages of the various elements (in sample C) as shown in Table 2. When compared to an area, shown in Figure 3 and represented as Spectrum 25; it was noticed that the particle (represented as Spectrum 29) has a higher silicon content (increased from 1\% to $11.73 \%$ ) and oxygen content (increased from $20.95 \%$ to $33.07 \%$ ). It is believed that this could either be a result of agglomeration of the silica particles during processing or the retention of the aerogel structure wherein, these particles are the unmodified silica aerogel. 

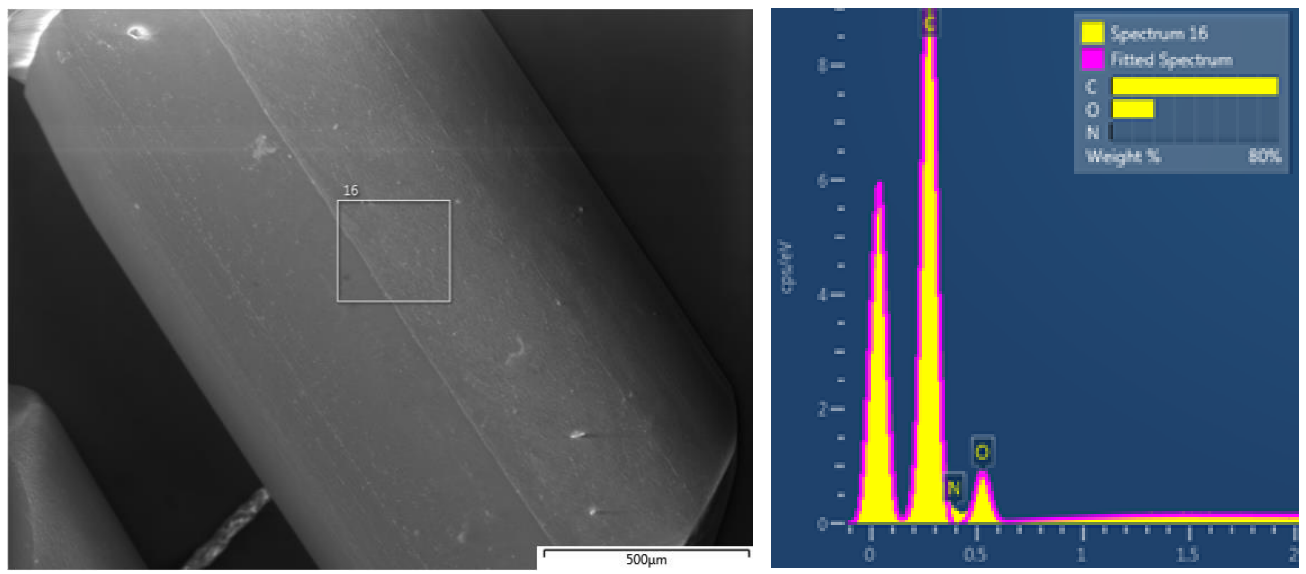

Figure 1 ESEM and EDX results of extruded PA-6 (Sample A). The image on the left is the ESEM image of the sample and the spectra on the right corresponds to the EDX spectra of the selected area in the microscopic image. $\mathrm{X}$-axis in $\mathrm{KeV}$.
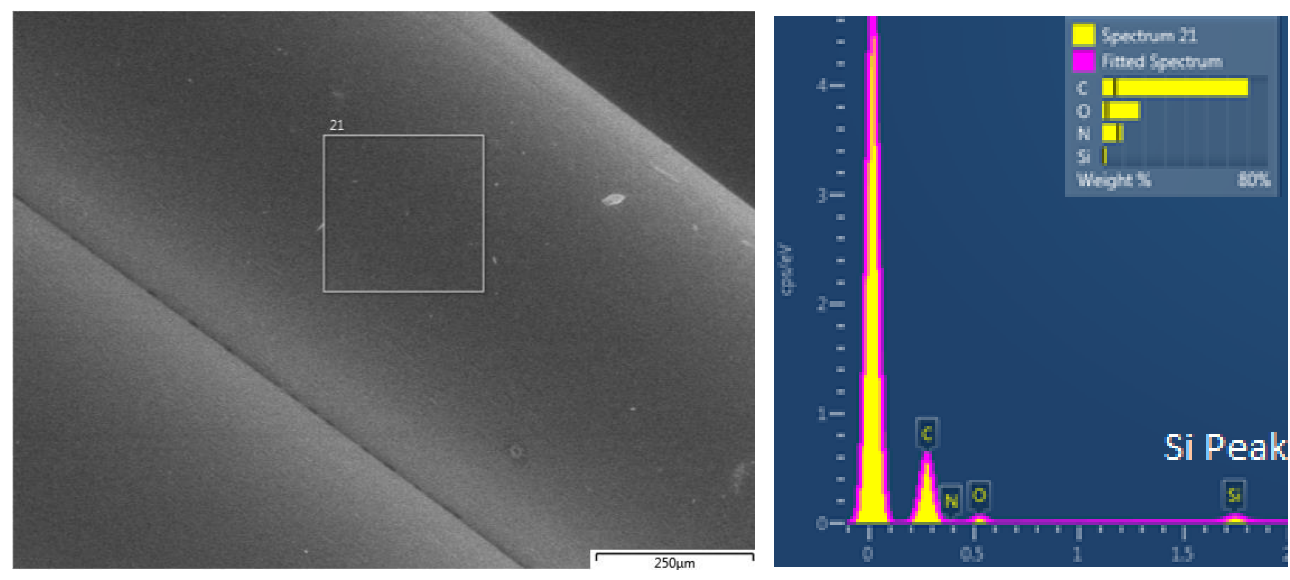

Figure 2 ESEM and EDX results of extruded PA-6 with SiO2 (Sample B). The image on the left is the ESEM image of the sample and the spectra on the right corresponds to the EDX spectra of the selected area in the microscopic image. $\mathrm{X}$-axis in $\mathrm{KeV}$. 

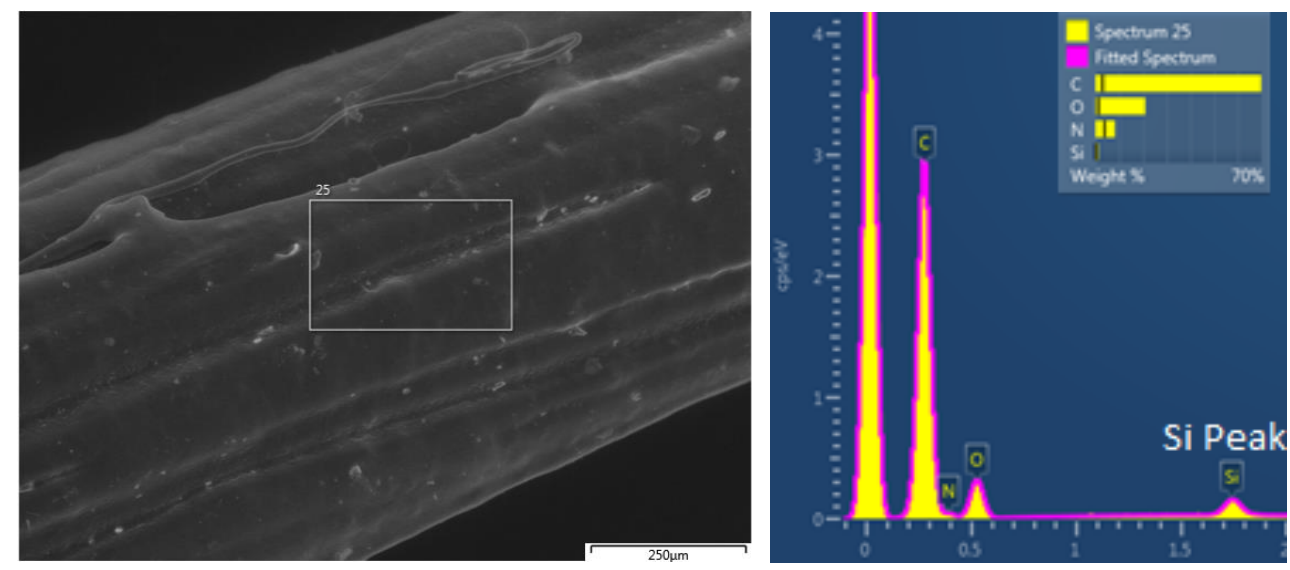

Figure 3 ESEM and EDX results of extruded PA-6 with $\mathrm{SiO} 2$ (Sample C). The image on the left is the ESEM image of the sample and the spectra on the right corresponds to the EDX spectra of the selected area in the microscopic image. $\mathrm{X}$-axis in $\mathrm{KeV}$ 

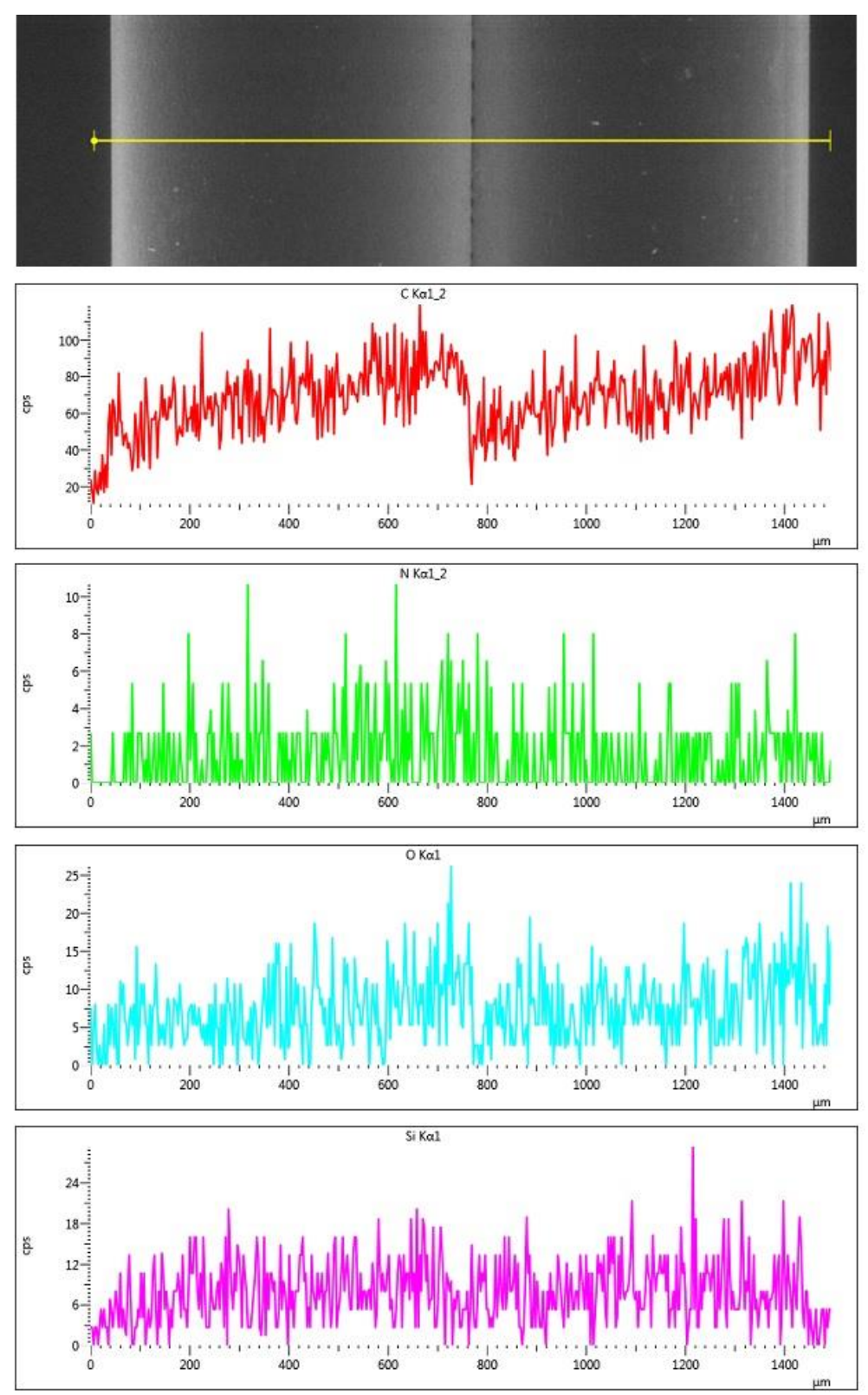

Figure 4 Line scan of a single extruded particle via SEM-EDX of Sample B for (top to bottom) Carbon (red),

Nitrogen (green), Oxygen (blue) and Silicon (purple). The vertical centre line in the sample is due to the application of a twin head die on the extruder and the subsequent joining of the two threads 

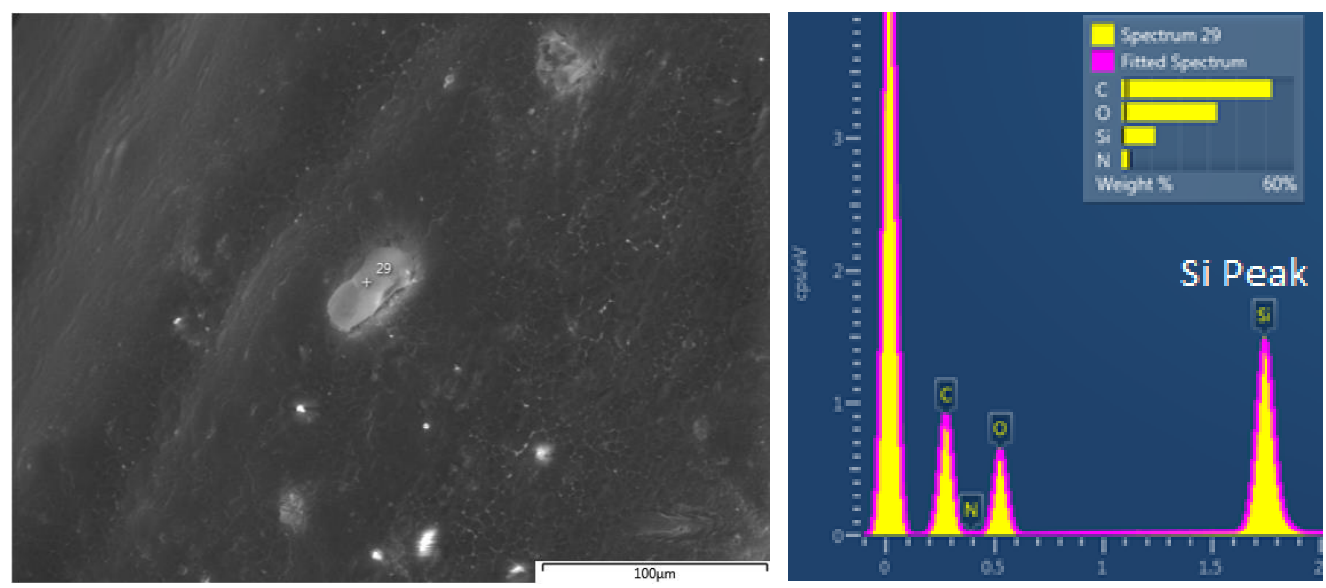

Figure 5 ESEM and EDX of a particle present in Sample C. The image on the left is the ESEM image of the sample and the spectra on the right corresponds to the EDX spectra of the selected spot in the microscopic image. $\mathrm{X}$-axis in $\mathrm{KeV}$.

Table 2 Weight percentages of the EDX Spectrums of Sample C

\begin{tabular}{|c|c|c|c|c|c|}
\hline Spectrum Label & $\mathbf{C}$ & $\mathbf{N}$ & $\mathbf{O}$ & $\mathbf{S i}$ & Total \% \\
\hline Spectrum 25 & 69.92 & 8.12 & 20.95 & 1 & 99.99 \\
\hline Spectrum 29 & 52.35 & 2.85 & 33.07 & 11.73 & 100 \\
\hline
\end{tabular}

Optical Microscope. The optical microscope showed a similar structure between samples A and B, however the ESEM and EDX results (discussed in the previous section) confirmed the presence of silica in Sample B, thereby suggesting that the aerogel structure completely collapsed in sample B. Further, Figure 6 indicates certain particle-like structures (circled in white) in sample B. It is believed that these are the silica particles that resulted from the destruction of the aerogel structure..

Sample C on the other hand, showed a different morphology compared to samples A and B. Additionally, there were certain regions within the sample that were darker (Figure 7) suggesting the presence of Silica; these regions being larger than the individual particles in sample B. It can also be inferred from the results that the aerogel structure was not 
completely destroyed as the silica particles stayed together. It is also possible that the pores within the aerogel could have been filled with the PA- 6 matrix during extrusion and compression pressing. Thus, the single run at 5 RPM showed an improvement compared to the previous attempts.

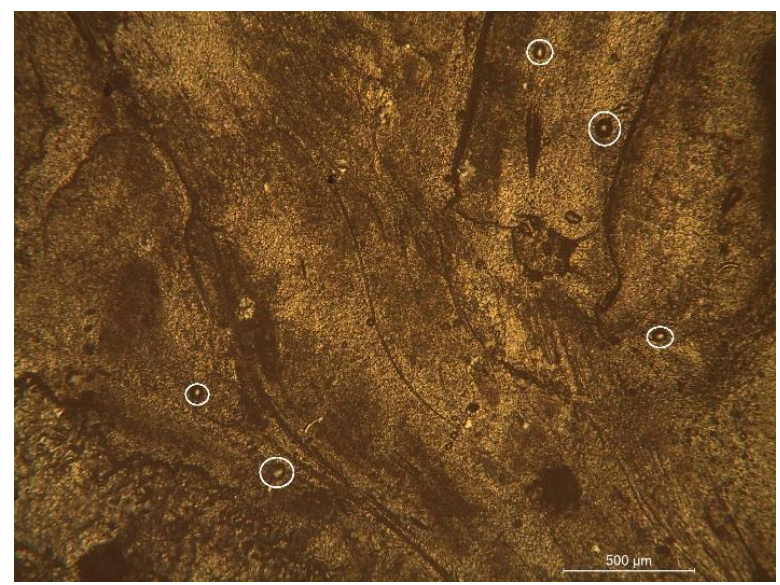

Figure 6 Sample B with possible Si particles (circled in white)

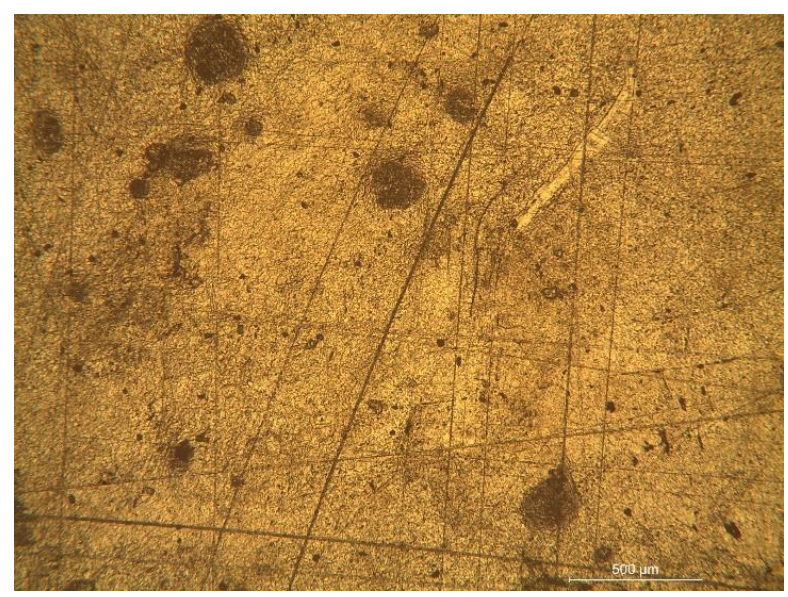

Figure 7 Sample C

\section{Density}

The density measurements were carried out on compression-moulded plates for the three samples. The average volume and mass measurements, along with the mean density for each sample is as tabulated in Table 3. To calculate the mean density, the density of three different 
specimens per sample was measured and then averaged. The results show us that the density of pure PA-6 is $1.02 \times 10^{6} \mathrm{~g} / \mathrm{m}^{3}$ which agrees well with the manufacture's number of $1.14 \times 10^{6}$ $\mathrm{g} / \mathrm{m}^{3}[18]$. The difference in the values could be due to the reduced accuracy of the measurement techniques used in the current work; the dimensions of the samples were measured using a line gauge, which has a least count of $1 \mathrm{~mm}$. However, the samples with the aerogel (B and C) show slightly decreased densities of $9.8 \times 10^{5} \mathrm{~g} / \mathrm{m}^{3}$ and $9.2 \times 10^{5} \mathrm{~g} / \mathrm{m}^{3}$ respectively: possibly due to the contribution of aerogel in the material. As predicted, samples $\mathrm{C}$ showed the lowest density, which could be due to their improved ability to retain the aerogel structure.

Table 3 Average density measurements

\begin{tabular}{|c|c|c|c|}
\hline Sample & A & B & C \\
\hline Mean Density $\left(\mathbf{g} / \mathbf{m}^{3}\right)$ & $1.02 \times 10^{6}$ & $9.8 \times 10^{5}$ & $9.2 \times 10^{5}$ \\
\hline
\end{tabular}

\section{Thermal Diffusivity}

Three samples were tested for thermal diffusivity, the average value for each type of sample was calculated [19] from the results obtained; one such set of diffusion maps is given in Figure 8 . Table 4 lists the average mean diffusivity and standard deviation values for the three samples; the average values were calculated using the mean diffusivity and the standard deviation measurements across three different specimens for each sample. 


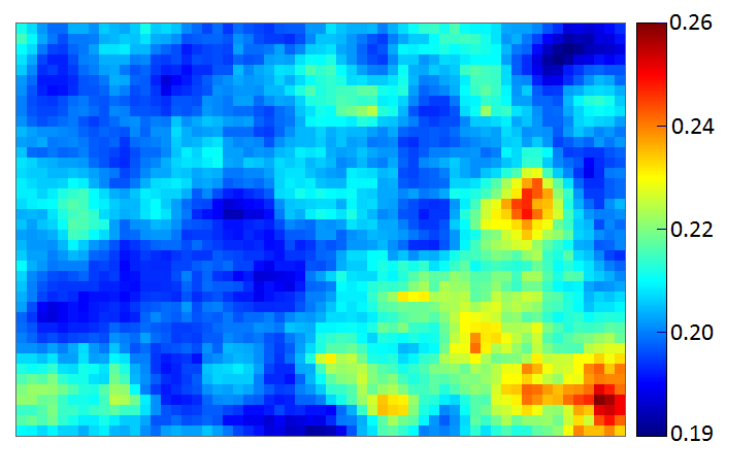

Sample A

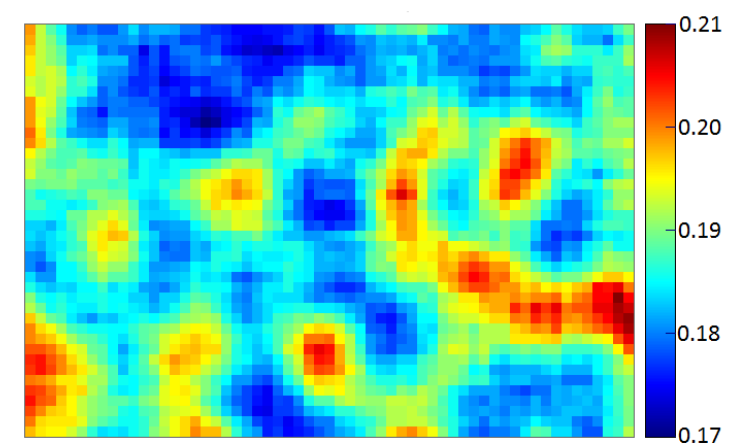

Sample B

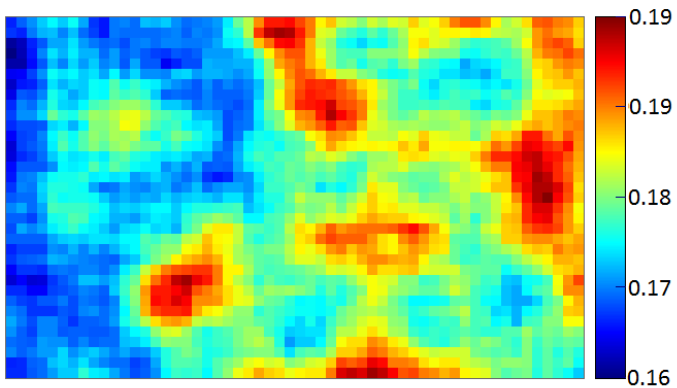

Sample C

Figure 8 Thermal diffusivity maps of Samples A, B, C where the diffusivity is indicated by the colour bar

Table 4 Average diffusivity and standard deviation values

\begin{tabular}{|c|c|c|}
\hline \multirow{2}{*}{ Sample } & \multicolumn{2}{|c|}{ Average Values } \\
\cline { 2 - 3 } & $\begin{array}{c}\text { Mean Diffusivity } \\
\left(\mathbf{m}^{2} / \mathbf{s}\right)\end{array}$ & Standard Deviation \\
\hline $\mathrm{A}$ & $2.34 \times 10^{-7}$ & 0.0340 \\
\hline $\mathrm{B}$ & $1.875 \times 10^{-7}$ & 0.0125 \\
\hline $\mathrm{C}$ & $1.7710 \times 10^{-7}$ & 0.0084 \\
\hline
\end{tabular}

From the measurement results in Table 4, it was observed that the PA-6/Aerogel composites showed lower diffusivity values compared to the pure PA-6 sample thereby, pointing to greater thermal insulation. Additionally, Sample C showed the lowest mean diffusivity value$1.7710 \times 10^{-7} \mathrm{~m}^{2} / \mathrm{s}$ confirming that the softer conditions during extrusion and pressing contributed to an improved thermal performance by retaining more aerogel (and its structure) within the composite. Further, it should be noted that the sample had the lowest average 
standard deviation suggesting that the sample has conducted heat more uniformly across a given cross section, thereby providing a potentially stronger thermal fatigue performance.

\section{Specific Heat Capacity}

The DSC profiles along with the baseline and sapphire standard calibration (both of which are needed for the specific heat calculation) for Samples A, B and C are given in Figure 9. From the graphs, it was observed that there is an endothermic peak close to $225^{\circ} \mathrm{C}$ for all the samples. It is believed that this was due to the melting of PA-6, which, according to the manufacture's data [20], is at $222^{\circ} \mathrm{C}$. Furthermore, sample $\mathrm{C}$ also showed an endothermic peak at around $395^{\circ} \mathrm{C}$ (unlike the other two samples) which was in addition to the previously mentioned endothermic peak at $225^{\circ} \mathrm{C}$.

Finally, the endothermic peak at $395^{\circ} \mathrm{C}$ in the DSC of sample $\mathrm{C}$ is thought to be due to the thermal degradation of nylon. Although the peak is only seen in sample C, a similar trend is observed in the other DSC graphs for samples A and B and it is predicted that they too, will show an endothermic speak (at a higher temperature). The reason for sample C's premature peak could be due to the destabilising effect of the aerogel as described by Levchik et al [21]. The authors studied the thermal decomposition of nylon 6 along with various fire retardants and concluded that the destabilisation of nylon 6 could reduce the thermal decomposition temperature by as much as $70^{\circ} \mathrm{C}$ (as in the case of ammonium polyphosphate). 

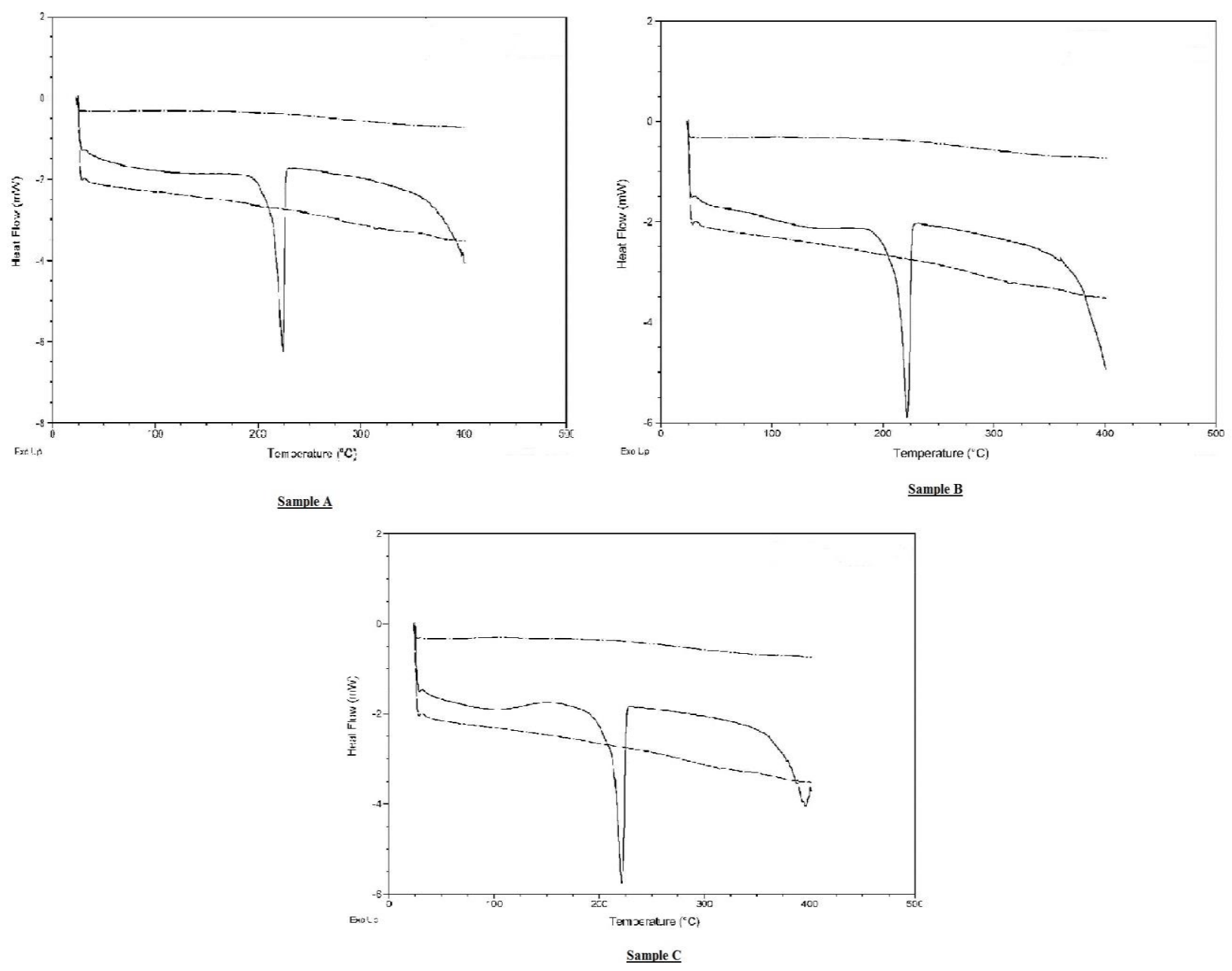

Figure 9 DSC maps of Samples A, B and C (solid line) with the baseline (dashed and dotted line) and sapphire standard (dashed line) curves imposed on them. The heat flow (in $\mathrm{mW}$ ) is on the $\mathrm{y}$-axis and the temperature (in ${ }^{\circ} \mathrm{C}$ is on the $\mathrm{x}$-axis)

\section{Calculations}

Specific Heat Capacity. The specific heat capacity of the samples was calculated using the DSC curves in Figure 9. The values of the specific heat capacity of the sapphire standard was taken from Ditmars et al [22] and the mass of the reference sample was measured to be $0.02626 \mathrm{~g}$. Because the specific heat capacity of the standard sapphire was given for every $10 \mathrm{~K}$, the closest value corresponding to the required temperature was considered. Therefore for example, if the specific heat capacity at $50^{\circ} \mathrm{C}(323 \mathrm{~K})$ was required, then the value 
corresponding to $320 \mathrm{~K}$ for the standard sapphire was chosen from [22]. The calculated specific heat capacity for the samples A, B and C are listed in Table 5 and graphically plotted in Figure 10.

Table 5 Specific Heat Capacity Calculation

\begin{tabular}{|c|c|c|c|}
\hline Sample & $\begin{array}{c}\text { Mass } \\
(\mathrm{g})\end{array}$ & $\begin{array}{c}\text { Temperature } \\
\left({ }^{\circ} \mathrm{C}\right)\end{array}$ & $\begin{array}{c}\text { Specific Heat } \\
\text { Capacity } \\
\left(\mathrm{J} /\left(\mathrm{g}^{0} \mathrm{C}\right)\right)\end{array}$ \\
\hline \multirow{4}{*}{ A } & \multirow{4}{*}{$7.47 \times 10^{-3}$} & 200 & 2.64 \\
\hline & & 150 & 2.45 \\
\hline & & 100 & 2.37 \\
\hline & & 50 & 1.84 \\
\hline \multirow{4}{*}{ B } & \multirow{4}{*}{$7.01 \times 10^{-3}$} & 200 & 3.39 \\
\hline & & 150 & 3.07 \\
\hline & & 100 & 2.78 \\
\hline & & 50 & 2.30 \\
\hline \multirow{4}{*}{$\mathrm{C}$} & \multirow{4}{*}{$6.44 \times 10^{-3}$} & 200 & 3.24 \\
\hline & & 150 & 2.64 \\
\hline & & 100 & 2.93 \\
\hline & & 50 & 2.41 \\
\hline
\end{tabular}

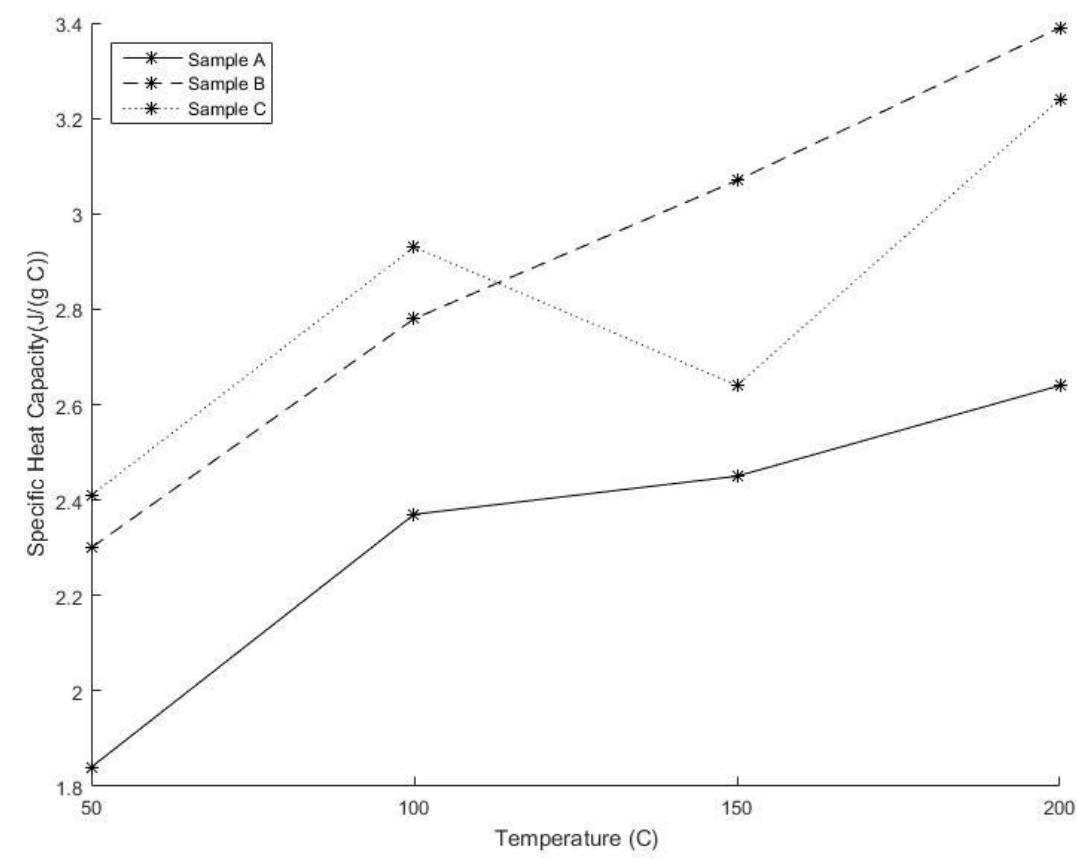

Figure 10 Specific heat capacities of PA-6/Aerogel Composites 
From Figure 10, it can be seen that sample A has lower values of specific heat across the whole temperature regime and that the specific heat of all the three samples increase with temperature. However, sample $\mathrm{C}$ exhibited a decrease between $100^{\circ} \mathrm{C}$ to $200^{\circ} \mathrm{C}$; this is shown in DSC curve as a broad endothermic peak (Figure 9).

Thermal Conductivity. The data for the density, thermal diffusivity and specific heat were taken from Table 3, Table 4 and Table 5 respectively. For thermal diffusivity and density, the average values were considered and for the specific heat; the value at $50^{\circ} \mathrm{C}$ for each of the sample was used since this was the closest to room temperature. The thermal conductivity values are presented in Table 6.

Table 6 Thermal conductivity calculation

\begin{tabular}{|c|c|c|c|}
\hline Sample & A & B & C \\
\hline Thermal Conductivity $(\mathbf{W} /(\mathbf{m} \mathbf{~ K}))$ & 0.44 & 0.42 & 0.39 \\
\hline
\end{tabular}

In order to analyse the calculated values of the thermal conductivity and to predict the amount of damage to the aerogel structure, a parameter known as the damage coefficient is defined.

\section{Damage Coefficient}

In this section, the damage of the aerogel structure in a polymer matrix is quantified by placing the calculated thermal conductivity of the samples in relation to the theoretical upper and lower thermal conductivities. The derived term known as the damage coefficient would allow an approximate mathematical measure of the destruction of the aerogel structure for the aerogel in a matrix.

The thermal conductivity values for the PA-6/Aerogel composite was theoretically calculated using the model described by Hamilton and Crosser [23]. This model enabled the calculation 
of the thermal conductivity for two-component heterogeneous mixtures. The values calculated analytically provide the upper and lower bounds for the composite in this study. The thermal conductivity of the composite determined using the thermal conductivity of the silica aerogel provides the lower bound whilst the value calculated using the thermal conductivity of normal silica (simulating the complete destruction of the aerogel structure) defines the upper bound.

For the purpose of data analysis a thermal conductivity value $\left(\mathrm{k}_{\mathrm{b}}\right)$ of $0.44 \mathrm{~W} /(\mathrm{mK})$ (from Table 6) was adopted for PA-6. For $\mathrm{k}_{\mathrm{a}}$, a value of $0.012 \mathrm{~W} /(\mathrm{mK})$ [24] (for the aerogel) was chosen together with a value of $1.4 \mathrm{~W} /(\mathrm{mK})$ [25] for pure silica. The volume fraction was calculated to be 0.327 (from a mass fraction of 0.04). The values of the theoretical thermal conductivity at the lower and upper bounds were calculated at $0.261 \mathrm{~W} /(\mathrm{m} \mathrm{K})$ and 0.651 $\mathrm{W} /(\mathrm{m} \mathrm{K})$ respectively.

Since, the theoretical bounds for the thermal conductivity of the composite used have now been calculated; a damage coefficient property is defined to assist the analysis. The damage coefficient (for the purpose of this study) is as given in equation (2).

$D_{c}=\frac{\left(k_{S}-k_{l}\right)}{\left(k_{u}-k_{l}\right)}$

Where $\mathrm{k}_{\mathrm{s}}=$ Thermal conductivity of the sample, $\mathrm{k}_{\mathrm{l}}=$ Lower bound thermal conductivity and $\mathrm{k}_{\mathrm{u}}=$ Upper bound thermal conductivity

Using equation (2), it is seen that the value of the damage coefficient $\left(D_{c}\right)$ at the lower and upper bounds are 0 and 1 respectively. This agrees with the previous assumption that when the aerogel structure is unaffected, then there is no damage; hence the damage coefficient $\left(D_{c}\right)$ is 0 . However, when there is complete destruction of the aerogel such that only silica particles (without the aerogel structure) are present then the value of $D_{c}$ becomes 1 . 
The results from Table 6 were used to determine the damage coefficient for samples B and C using equation (2) wherein, the calculated values are 0.41 and 0.33 respectively.

\section{Discussion}

The research in this paper compares the thermal conductivity of PA-6/Aerogel composites extruded using two different extrusion speeds; $65 \mathrm{rpm}$ and $5 \mathrm{rpm}$. The results point towards a lower thermal conductivity for the material processed using a lower extrusion speed. Additionally, a damage coefficient to quantify the loss of the aerogel structure, was defined. When considering the values of the damage coefficients, sample B and sample $\mathrm{C}$ show values of 0.41 and 0.33 respectively; this could roughly be translated as sample B losing the structure of around $41 \%$ of the aerogel and sample $\mathrm{C}$ loosing around $33 \%$ of its aerogel. Therefore, although the lower extrusion conditions of sample $\mathrm{C}$ did provide a relatively better material with reference to thermal conductivity through a better retention of the aerogel structure, it is believed that the compression moulding contributed to the destruction of a significant number of the aerogel particles within the sample. This statement is based on the initial ESEM and optical microscope studies, which pointed to an improvement in the retention of the aerogel in sample C compared to B. Further, it can be evidenced from the literature that the thermal conductivity of the 'as-extruded' aerogel/Nylon (MXD6) composite reduced as much as $47 \%$ when compared to the virgin polymer [13]. However, when comparing the results obtained in this study, it is seen that even sample C's value (which achieved the lowest thermal conductivity of all the samples tested) was only around $11 \%$ lower than that of sample A. Therefore, further research must look to negating this effect of compression moulding by either studying the moulding parameters and/or other processing techniques which builds upon the initial advantage offered by the lower extrusion speeds. 
This is thought to be critical because the final moulding (of the extruded material into its final shape) is important for the material to attain the required shape for practical applications.

It must also be noted that the damage coefficient to the aerogel was predicted purely based on the thermal conductivity results. For a more accurate description, additional material properties must be evaluated and incorporated into the calculation. One such method could incorporate an evolution of equation (2) into equation (3).

$D_{c}=\frac{\sum n\left(\frac{\left(P_{S}-P_{l}\right)}{\left(P_{u}-P_{l}\right)}\right)}{n}$

Where $\mathrm{P}_{\mathrm{s}}=$ Required property of the sample, $\mathrm{P}_{1}=$ Lower bound of the required property, $\mathrm{P}_{\mathrm{u}}=$ Upper bound of the required property and $n=$ Number of properties tested.

The results in this study do show some promising trends with respect to the thermal conductivity values with the aerogel composites showing lower thermal conductivity values. A similar trend was also seen in the work of Jabbari et al.[26] who show the reduction of thermal conductivity for a poly(vinyl chloride) matrix containing aerogel. This is believed to be due to the Knudsen effect which allows aerogels to have high insulation capabilities as discussed by Raed \& Gross in Jabbari et al.[26]. When comparing the results of sample's B and $\mathrm{C}$, it is observed the lower speeds of the extruder for sample $\mathrm{C}$ helped preserve more aerogel and hence a lower thermal conductivity. Additionally, because sample $\mathrm{C}$ showed a lower standard deviation during thermal diffusivity measurements, it is suggested that there would be a lower temperature gradient across its cross section during heat transfer and could result in a better thermal aging and fatigue performance. The more uniform distribution of heat in sample $\mathrm{C}$ also point towards a homogenous material and good mixing of the aerogel 
particles within the PA-6 matrix, thereby negating one of the limitations of using lower extrusion speeds

It is therefore recommended that although there was a significant damage to the aerogel during the processing of the samples, further research especially towards alternatives to compression moulding would enable the production of an aerogel/PA-6 composite with superior thermal conductivity and a more efficient thermally insulating material. Finally, further testing with reference to the material's mechanical properties would be beneficial in determining its practical applicability.

\section{Conclusions}

Aerogel/PA-6 composites were mixed using a twin screw extruder and moulded using a compression press using two different speeds in the extruder (along with a pure nylon sample as a control). According to the experimental results, both composite samples had a lower thermal conductivity compared to the virgin polymer with the lower rpm sample showing improved thermal performance $(0.39 \mathrm{~W} /(\mathrm{mK}))$ compared with the batch processed using a higher rpm $(0.42 \mathrm{~W} /(\mathrm{mK}))$. These results were also corroborated with the calculated damage coefficient values. The damage coefficient allowed a quantification of the damaged aerogel structure and the equation described in this paper can be used for similar aerogel/polymer composites.

These results thus point to a promising direction for thermal insulation materials, but more research is required to optimise the final moulding process since it is thought that the majority of the aerogel was destroyed in this step, especially for the samples with a lower extrusion speed, as observed with the microscopic and EDX images.

\section{Acknowledgements}


The authors would like to thank Mr. Jim Hurley, Mr. Andrew Stallard, Dr. Christine Kimpton and Dr. David Ayre for assistance during the preparation and testing of the samples. The experimental data along with the full resolution images supporting this paper is made available at: https://figshare.com/s/16635f889b0cd95c84f5

\section{References}

[1] S. S. Kistler, “Coherent Expanded Aerogels and Jellies,” Nature, vol. 127, no. 3211, p. $741,1931$.

[2] N. Gupta and W. Ricci, "Processing and compressive properties of aerogel/epoxy composites,” J. Mater. Process. Technol., vol. 198, no. 1-3, pp. 178-182, Mar. 2008.

[3] M. Schmidt and F. Schwertfeger, "Applications for silica aerogel products," J. Non. Cryst. Solids, vol. 225, pp. 364-368, 1998.

[4] L. W. Hrubesh, “Aerogel applications,” J. Non. Cryst. Solids, vol. 225, pp. 335-342, 1998.

[5] J. Koravos, C. Norwood, P. Pescatore, and J. Pidhurney, "Aerogel Insulative Coatings: New Coating Technology Offers Personnel Protection," Paint and Coatings Industry, 2013. [Online]. Available: http://www.pcimag.com/articles/98016-aerogel-insulativecoatings. [Accessed: 12-Feb-2016].

[6] D. Ge, L. Yang, Y. Li, and J. Zhao, "Hydrophobic and thermal insulation properties of silica aerogel/epoxy composite,” J. Non. Cryst. Solids, vol. 355, no. 52-54, pp. 26102615, Dec. 2009.

[7] S. Y. Kim, Y. J. Noh, J. Lim, and N.-H. You, "Silica aerogel/polyimide composites 
with preserved aerogel pores using multi-step curing," Macromol. Res., vol. 22, no. 1, pp. 108-111, Jan. 2014.

[8] M. A. B. Meador, E. F. Fabrizio, F. Ilhan, A. Dass, G. Zhang, P. Vassilaras, J. C. Johnston, and N. Leventis, "Cross-linking Amine-Modified Silica Aerogels with Epoxies: Mechanically Strong Lightweight Porous Materials," Chem. Mater., vol. 17, no. 5, pp. 1085-1098, Mar. 2005.

[9] T.-Y. Wei, S.-Y. Lu, and Y.-C. Chang, "Transparent, Hydrophobic Composite Aerogels with High Mechanical Strength and Low High-Temperature Thermal Conductivities,” J. Phys. Chem. B, vol. 112, no. 38, pp. 11881-11886, Sep. 2008.

[10] M. Mielke and K.-H. von Dungen, "Moldings containing silica aerogel particles and their preparation."

[11] V. Vo, M. I. Maurer, F. Bunge, and H. H. Merkel, "Thermally insulating polymer foam/aerogel composite articles."

[12] G. S. Kim and S. H. Hyun, "Effect of mixing on thermal and mechanical properties of aerogel-PVB composites,” J. Mater. Sci., vol. 38, no. 9, pp. 1961-1966, 2003.

[13] M. K. WILliAMS, T. M. SMITH, J. E. Fesmire, L. B. ROBERSON, and L. M. CLAYTON, "Aerogel/polymer composite materials."

[14] C. Rauwendaal, Polymer Extrusion. Munich: Carl Hanser Verlag, 1986.

[15] D. Halliday, R. Resnick, and J. Walker, Fundamentals of physics, 7th ed. Hoboken, NJ: Wiley, 2005.

[16] M. J. O’neill, “Measurement of Specific Heat Functions by Differential Scanning Calorimetry.," Anal. Chem., vol. 38, no. 10, pp. 1331-1336, 1966. 
[17] Thermal Wave Imaging Inc., "ThermoScope ${ }^{\circledR}$ II: Advanced Thermography for InService Inspection.” [Online]. Available:

http://www.thermalwave.com/1/376/thermoscope_ii.asp. [Accessed: 16-Nov-2016].

[18] "Durethan B30 S 000000 Data Sheet," 2016. [Online]. Available: https://techcenter.lanxess.com/scp/americas/en/products/datasheet/LANXESS_Duretha n_B_30_S_000000_ISO_EN.pdf?docId=187277. [Accessed: 04-Sep-2016].

[19] S. Shepard, "Automated binary processing of thermographic sequence data."

[20] Durethan B 30 S 000000, “Safety Data Sheet.” Lanxess Corporation, 2012.

[21] S. V. Levchik, G. F. Levchik, A. I. Balabanovich, G. Camino, and L. Costa, "Mechanistic study of combustion performance and thermal decomposition behaviour of nylon 6 with added halogen-free fire retardants," Polym. Degrad. Stab., vol. 54, no. 2, pp. 217-222, Nov. 1996.

[22] D. A. Ditmars, S. Ishihara, S. S. Chang, G. Bernstein, and E. D. West, "Enthalpy and heat-capacity standard reference material: synthetic sapphire (a-Al2O3) from 10 to 2250 K,” J. Res. Natl. Bur. Stand. (1934)., vol. 87, no. 2, pp. 159-163, 1982.

[23] R. L. Hamilton and O. K. Crosser, "Thermal conductivity of heterogeneous twocomponent systems," Ind. Eng. Chem. Fundam., vol. 1, no. 3, pp. 187-191, 1962.

[24] “BuyAerogel.com | Enova® Aerogel IC3110 Particles.” [Online]. Available: http://www.buyaerogel.com/product/enova-aerogel-ic3110/. [Accessed: 08-Aug-2016].

[25] “Silica-Silicon Dioxide ( $\mathrm{SiO} 2)$ properties.” [Online]. Available: http://www.azom.com/properties.aspx?ArticleID=1114. [Accessed: 29-Sep-2016].

[26] M. Jabbari, D. Akesson, M. Skrifvars, and M. J. Taherzadeh, "Novel lightweight and 
highly thermally insulative silica aerogel-doped poly(vinyl chloride)-coated fabric composite," J. Reinf. Plast. Compos., vol. 34, no. 19, pp. 1581-1592, 2015. 
2017-10-03

Effect of extrusion and compression moulding on the thermal properties of nylon-6/silica aerogel composites

Krishnaswamy, Suryanarayanan

SAGE

Krishnaswamy S, Tinsley L, Marchante V, Addepalli S, Huang Z, Abhyankar H, Effect of extrusion and compression moulding on the thermal properties of nylon-6/silica aerogel composites, Journal of Thermoplastic Composite Materials, Vol 31, Issue 7, 2018, pp992-1009 https://doi.org/10.1177/0892705717729198

Downloaded from Cranfield Library Services E-Repository 